\title{
Microbiota da flora intestinal de besouros (Coleoptera: Scarabaeidae) do Parque Olhos D'Água
}

\author{
Rafael Vieira Nunes ${ }^{1}$ \\ Marina Regina Frizzas ${ }^{2}$
}

\section{Resumo}

Interações entre microrganismos e insetos são comuns na natureza podendo apresentar importância médica, agrícola ou ecológica. O presente estudo teve como objetivo verificar a ocorrência de fungos e bactérias provenientes da flora intestinal de besouros da família Scarabaeidae, bem como avaliar a diversidade do grupo no Parque Olhos D’Água, em Brasília, DF. Os besouros foram coletados por meio de alçapão, armadilha luminosa e coletas manuais durante o período de outubro de 2006 a maio de 2007. Os insetos coletados tiveram seus tratos digestivos retirados e cultivados em meios para crescimento de fungos e bactérias. Dezesseis espécies de Scarabaeidae foram coletadas e seis foram analisadas. Em todas, houve crescimento de bactérias de importância médica como Staphylococcus sp. Dentre os fungos, os pertencentes à família Saccharomycetaceae apresentaram o maior número de espécies. Os Scarabaeidae possuem uma flora intestinal rica e são carreadores e dispersores potenciais de microorganismos.

Palavras-chave: Entomofauna. Rola-bosta. Trato digestivo. Parque Urbano.

\section{Introdução}

Os besouros da família Scarabaeidae são popularmente conhecidos como besouros escaravelhos ou rola-bosta. Totalizam, aproximadamente, 4.500 espécies no mundo e mais de 1700 no Brasil (HALFFTER; MATTHEWS, 1966; COSTA, 1997;

\footnotetext{
${ }^{1}$ Graduando do Curso de Biologia do Centro Universitário do Brasília - UniCEUB, bolsista do Programa de Iniciação Científica, PIC-UniCEUB.

${ }^{2}$ Doutora em Entomologia pela Escola Superior de Agricultura Luiz de Queiroz, USP/ESALQ, Brasil. Professora do Centro Universitário de Brasília - UniCEUB.
} 
VAZ-DE-MELLO, 1999). Existem muitas divergências taxonômicas em relação à posição da família na ordem Coleoptera, o que dificulta uma classificação de consenso para o grupo (SCHIFFLER; LOUZADA, 2003). Neste trabalho, optou-se por estudar os representantes da superfamília Scarabaeioidea, representada pelas famílias Scarabaeidae e Melolonthidae, caracterizando a expressão Scarabaeidae sensu lato (KOHLMANN; MORÓN, 2003).

Os Scarabaeidae sensu lato possuem ecologia diversificada e complexa, são fitófagos, consumindo variadas partes das plantas, dispersores de sementes no ecossistema e decompositores de matéria orgânica, como restos vegetais, carcaças de animais e fezes (MILHOMEN et al., 2003; MORÓN; ARAGÓN, 2003). Devido aos seus hábitos alimentares variados, é provável que os Scarabaeidae, assim como diversos outros insetos, tenham uma flora intestinal rica em microrganismos. Steinhaus (1941) estudou a flora bacteriana de 30 espécies de insetos e constatou a presença de mais de 20 espécies de bactérias habitantes do trato digestivo desses insetos. Moraes et al. (2004) estudaram a presença de fungos na flora intestinal de vetores do Trypanossoma cruzi Chagas, 1909, e constataram a presença de 34 espécies de fungos. A dispersão de fungos e bactérias de importância médica, por formigas e baratas, em leitos de hospitais, também, já foi relatada em dois estudos (MOREIRA et al., 2003; LEMOS et al., 2006). No aspecto ecológico e agrícola, a utilização de microrganismos, principalmente fungos, no controle biológico de insetos-praga reforça a importância das relações entre microrganismos e insetos na natureza (BOTELHO et al., 2002).

Os objetivos desse estudo foram verificar a ocorrência de fungos e bactérias na flora digestiva de besouros da família Scarabaeidae e realizar um levantamento das espécies no Parque Ecológico Olhos D’Água, localizado em Brasília, DF.

\section{Materiais e Métodos}

\section{1 Área de Coleta}

O Parque Ecológico Olhos D'Água localiza-se nas Quadras SQN 413/414 e SCLN 414/415, no Bairro da Asa Norte, em Brasília, DF. Possui área de 21,6 hectares dividida em mata de galeria, cerrado sensu stricto alterado, lagoa formada por dois córregos e área de convivência destinada aos usuários do Parque (MACEDO, 2003). À 
Leste, o Parque Olhos D’Água é delimitado pela avenida L2 e por uma área contígua que contém formações de cerrado sensu sctricto e mata de galeria - essa área é denominada Arboreto.

\subsection{Coleta de insetos}

Foram utilizados três métodos de coleta: alçapão com isca atrativa, armadilha luminosa e coletas manuais, constituídas por rondas nos locais de coleta. $\mathrm{O}$ alçapão consiste de um cilindro de $10 \mathrm{~cm}$ de diâmetro e $15 \mathrm{~cm}$ de altura, enterrado ao nível do solo, a isca é colocada em um recipiente menor, de $4 \mathrm{~cm}$ de diâmetro e $5 \mathrm{~cm}$ de altura, suspenso por arames finos, para que não haja contato da isca com a amostra coletada (MILHOMEN et al., 2003) .

A armadilha luminosa é formada por um funil de alumínio de $65 \mathrm{~cm}$ de altura. O diâmetro maior do funil tem cerca de $37 \mathrm{~cm}$; o cone do funil, $40 \mathrm{~cm}$ de comprimento; o tubo do funil $25 \mathrm{~cm}$ de altura. Sobre o maior diâmetro do funil, encaixa-se uma armação feita com quatro aletas de alumínio, de $45 \mathrm{~cm}$ de altura por $14 \mathrm{~cm}$ de largura cada uma, disposta de maneira cruzada ao redor de uma lâmpada fluorescente (ALMEIDA; MARINONI, 2002).

As coletas foram realizadas quinzenalmente, de outubro de 2006 a maio de 2007. As armadilhas foram instaladas no período matutino e permaneceram 24 horas no Parque Olhos D’Água. A cada coleta, foram utilizados cinco alçapões e uma armadilha luminosa. As armadilhas permaneceram um dia e uma noite no campo. No alçapão e na armadilha luminosa, o álcool 70\% foi trocado por água com detergente, a fim de evitar a esterilização do trato digestivo dos insetos.

Após a coleta dos insetos, esses foram separados em morfoespécies e depositados em uma coleção de referência particular. A identificação quanto a gênero e espécie foi realizada por comparação com o material do museu de entomologia da ESALQ/ USP e com o auxílio do Prof. Dr. Sinval Silveira Neto. Os insetos destinados à análise microbiológica foram armazenados em frascos estéreis e congelados, a fim de interromper o crescimento dos microorganismos associados aos besouros.

\subsection{Análise microbiológica}

Os tratos digestivos foram analisados no laboratório de Microbiologia do UniCEUB. Inicialmente, os insetos foram imersos, por um minuto, em solução de hipo- 
clorito de sódio $0,5 \%$, posteriormente, foram lavados com água destilada estéril conforme procedimentos de Moraes et al. (2004). Após a esterilização, pernas, élitros e asas membranosas dos besouros foram retirados. Um corte ao longo da parte ventral do abdômen permitiu a retirada do trato digestivo do inseto, que foi dividido e distribuído em meios de enriquecimento para fungos e bactérias. O meio utilizado para bactérias foi "Brain-heart infusion" (BHI), a $37^{\circ} \mathrm{C}$, por 48 horas (MOREIRA et al., 2003). Quando detectado o crescimento de bactérias no meio, as amostras foram identificadas por testes bioquímicos, seguindo procedimentos de Steinhaus (1941).

Os fungos foram cultivados, inicialmente, em meio líquido YG, a $28^{\circ} \mathrm{C}$, por 7 dias. Após crescimento das colônias, os fungos foram isolados em placas de petri, contendo meio de cultura Batata-Dextrose-Agar (BDA) (MORAES et al., 2004). A identificação foi feita com base em comparação de morfologia das colônias cultivadas e teve auxílio da Dra. Maria José Charchar, da Embrapa Cerrados.

Além das espécies coletadas, o besouro Digitonthophagus gazella Fabricius, 1787, da subfamília Coprinae, nativo da África e trazido ao Brasil pela Embrapa, para controle biológico (KOLLER et al., 2002), também foi analisado quanto ao trato digestivo. Os exemplares da espécie foram cedidos pelo laboratório de Parasitologia da Embrapa Cerrados.

\section{Resultados}

Ao todo, foram coletados 81 besouros, divididos em 16 espécies. A espécie mais coletada foi Dichotomius ascanius, todos coletados em alçapão com iscas. O gênero Cyclocephala sp. teve 11 indivíduos coletados manualmente, distribuídos em três espécies. As coletas com alçapão permitiram obter 42 indivíduos (51,9\% do total), as coletas manuais, 27 indivíduos (33,3\% do total) e com armadilha luminosa, 12 besouros ( $14,8 \%$ do total) (tabela 1$)$.

Devido ao número limitado de indivíduos coletados, apenas seis espécies de besouros foram analisadas quanto à presença de fungos na flora intestinal. Ao total, treze espécies de fungos foram isoladas. As leveduras ascomicéticas da família Saccharomycetaceae estavam presentes em todos os tratos digestivos analisados. A família Laboulbeniomycetidae estava presente em três espécies de insetos. 
Tabela 1 - Subfamília, espécie, método, época e local de coleta de besouros da família Scarabaeidae no Parque Olhos D’Água, Brasília, DF, no período de outubro de 2006 a maio de 2007.

\begin{tabular}{|c|c|c|c|}
\hline Espécie & $\begin{array}{c}\text { No de } \\
\text { indivíduos }\end{array}$ & $\begin{array}{c}\text { Método e } \\
\text { Local de coleta }\end{array}$ & $\begin{array}{c}\text { Época de } \\
\text { coleta }\end{array}$ \\
\hline Dichotomius ascanius & 34 & $\begin{array}{c}\text { Alçapão/Mata de } \\
\text { galeria }\end{array}$ & $\begin{array}{c}\text { Março a } \\
\text { maio de } 2007\end{array}$ \\
\hline Scarabaeidae sp. 19 & 4 & $\begin{array}{l}\text { Alçapão/ Cerrado } \\
\text { sensu stricto }\end{array}$ & $\begin{array}{l}\text { Março de } \\
2007\end{array}$ \\
\hline Scarabaeidae sp. 12 & 3 & $\begin{array}{c}\text { Alçapão/Mata de } \\
\text { galeria }\end{array}$ & $\begin{array}{l}\text { Março de } \\
2007\end{array}$ \\
\hline Scarabaeidae sp. 20 & 1 & $\begin{array}{c}\text { Alçapão/Mata de } \\
\text { galeria }\end{array}$ & $\begin{array}{l}\text { Março de } \\
2007\end{array}$ \\
\hline Scarabaeidae sp. 12 & 8 & $\begin{array}{c}\text { Armadilha luminosa/ } \\
\text { Mata de galeria }\end{array}$ & $\begin{array}{l}\text { Março de } \\
2007\end{array}$ \\
\hline Leucothyreus sp. & 4 & $\begin{array}{c}\text { Armadilha luminosa/ } \\
\text { Mata de galeria }\end{array}$ & $\begin{array}{l}\text { Março de } \\
2007\end{array}$ \\
\hline Aegopsis bolboceridus & 6 & $\begin{array}{c}\text { Coleta manual/Todo o } \\
\text { parque }\end{array}$ & $\begin{array}{c}\text { Outubro de } \\
2006\end{array}$ \\
\hline Cyclocephala forsteri & 5 & $\begin{array}{c}\text { Coleta manual/Todo o } \\
\text { parque }\end{array}$ & $\begin{array}{l}\text { Janeiro de } \\
2007\end{array}$ \\
\hline Cyclocephala sp. & 5 & $\begin{array}{c}\text { Coleta manual/Todo o } \\
\text { parque }\end{array}$ & $\begin{array}{l}\text { Janeiro de } \\
2007\end{array}$ \\
\hline Heterogomphus ulysses & 2 & $\begin{array}{c}\text { Coleta manual/ } \\
\text { Cerrado sensu stricto }\end{array}$ & $\begin{array}{l}\text { Janeiro de } \\
2007\end{array}$ \\
\hline Oxysternon palaemon & 2 & $\begin{array}{c}\text { Coleta manual/Todo o } \\
\text { parque }\end{array}$ & $\begin{array}{l}\text { Outubro de } \\
2006\end{array}$ \\
\hline $\begin{array}{l}\text { Scarabaeidae sp. } \\
6\end{array}$ & 2 & $\begin{array}{c}\text { Coleta manual/ Mata } \\
\text { de galeria }\end{array}$ & $\begin{array}{c}\text { Abril de } \\
2007\end{array}$ \\
\hline Allorhina cornifrons & 1 & $\begin{array}{c}\text { Coleta manual/Sede } \\
\text { do parque }\end{array}$ & $\begin{array}{l}\text { Outubro de } \\
2006\end{array}$ \\
\hline Gymnetis rufolatris & 1 & $\begin{array}{c}\text { Coleta manual/ } \\
\text { Adjacências do parque }\end{array}$ & $\begin{array}{c}\text { Dezembro de } \\
2006\end{array}$ \\
\hline $\begin{array}{l}\text { Cyclocephala } \\
\text { melanocephala }\end{array}$ & 1 & $\begin{array}{c}\text { Coleta manual/ } \\
\text { Adjacências do parque }\end{array}$ & $\begin{array}{c}\text { Janeiro de } \\
2007\end{array}$ \\
\hline $\begin{array}{c}\text { Anomala } \\
\text { testaceipennis }\end{array}$ & 1 & $\begin{array}{c}\text { Coleta manual/ } \\
\text { Adjacências do parque }\end{array}$ & $\begin{array}{c}\text { Dezembro de } \\
2006\end{array}$ \\
\hline Pelidnota palidipennis & 1 & $\begin{array}{c}\text { Coleta manual/ } \\
\text { Adjacências do parque }\end{array}$ & $\begin{array}{c}\text { Dezembro de } \\
2006\end{array}$ \\
\hline
\end{tabular}


Aspergillus niger, Penicillium sp., Cladosporium sp e Mucor sp. ocorreram duas vezes cada um. Em todos os insetos, houve, no mínimo, crescimento de duas espécies de fungos (tabela 2).

Tabela 2 - Fungos isolados da flora intestinal de besouros Scarabaeidae coletados no Parque Olhos D'Água em Brasília.

\begin{tabular}{cc}
\hline Espécie de Besouro & Espécie de Fungo \\
\hline & Cladosporium sp. \\
Aspergillus niger \\
Dichotomius ascanius & Saccharomycetaceae sp. 1 \\
& Saccharomycetaceae sp. 2 \\
& Laboulbeniomycetidae sp. 1 \\
Leucothyreus sp. & Saccharomycetaceae sp. 3 \\
& Mucor sp. \\
Scarabaeidae sp. 19 & Cladosporium sp. \\
& Laboulbeniomycetidae sp. 2 \\
& Laboulbeniomycetidae sp. 1 \\
Cyclocephala forsteri & Penicillium sp. \\
& Saccharomycetaceae sp. 4 \\
Syclocephala sp. & Saccharomycetaceae sp. 5 \\
& Laboulbeniomycetidae sp. 3 \\
& Mucor sp. \\
& Saccharomycetaceae sp. 4 \\
Digitonthophagus gazella & Saccharomycetaceae sp. 5 \\
& Mucor sp. \\
& Penicillinium sp. \\
& Aspergillus niger \\
& Saccharomycetaceae sp. 6 \\
\hline
\end{tabular}

$\mathrm{Na}$ análise bacteriana, foram isoladas seis espécies de bactérias provenientes do trato digestivo de quatro espécies de besouro. D. ascanius e D. gazella foram as espécies que mais apresentaram crescimento de microrganismos, três espécies no total. O gênero Staphylococcus estava presente em todos os tratos digestivos. Outras espécies de bactérias isoladas foram Enterococcus sp1 e sp2, Escherichia coli, Salmonella sp. e duas espécies de Enterococcus spp (tabela 3). 


\section{Discussão}

Das espécies identificadas, $D$. ascanius é um registro novo para a lista de Scarabaeidae sensu stricto (subfamílias Coprinae e Scarabaeinae) no Distrito Federal. Outras 10 espécies constituem novos registros para o Distrito Federal e para o Cerrado, já que não existem levantamentos relativos à família Melolonthidae no DF (MILHOMEN et al., 2001).

Tabela 3 - Bactérias isoladas da flora intestinal de besouros Scarabaeidae coletados no Parque Olhos D'Água em Brasília.

\begin{tabular}{cc}
\hline Espécie de Besouro & Espécie de Bactéria \\
\hline Dichotomius ascanius & Enterococcus $\mathrm{sp} .1$ \\
Leucothyreus sp. & Salmonella sp. \\
& Staphylococcus $\mathrm{sp}$. \\
Scarabaeidae sp. 19 & Enterococcus sp. 1 \\
& Staphylococcus $\mathrm{sp}$. \\
Digitonthophagus gazella & Enterococcus sp. 2 \\
& Escherichia coli \\
& Staphylococcus $\mathrm{sp}$.
\end{tabular}

A família Saccharomycetaceae, das leveduras ascomicéticas, foi a mais abundante nas análises de fungos, com seis morfoespécies descritas. Segundo Phaff e Starmer (1987), a associação de leveduras com insetos é de grande importância ecológica, pois os insetos utilizam produtos derivados do metabolismo das leveduras, como os carboidratos. Várias espécies dessa família de fungos têm sido associadas a outras famílias de Coleopteros, como Bostrichidae, Cerambycidae, Buprestidae e Curculionidae (BARRETO et al., 1998). A família Laboulbeniomycetidae pertence à ordem Laboulbeniales e está representada por três espécies no estudo. São fungos parasitas obrigatórios de artrópodes, que, na maioria dos insetos, se alojam apenas no tegumento quitinoso, podendo, em alguns casos, parasitar órgãos internos. Raramente o inseto é seriamente afetado (PUTZKE; PUTZKE, 2004). 
Os fungos Penicillium sp. e Aspergillus niger têm importância médica e são comumente encontrados na natureza. Ao lado de Mucor sp., tais espécies já foram descritas para espécies de besouros, percevejos, formigas e baratas (GAMA et al., 2002; MOREIRA et al., 2003; MORAES et al., 2004; LEMOS et al., 2006). Cladosporium sp. é um fungo utilizado em controle biológico de insetos por ser entomopatogênico (OLIVEIRA et al., 2004).

O gênero de bactéria Staphylococcus foi o mais freqüente nas análises. Uma das espécies identificada, Staphylococcus faecalis, é comum em fezes e é causadora de algumas infecções no trato digestivo urinário em seres humanos (MADINGAN et al., 2004). Enterococcus sp. é comumente encontrada em fezes de diversos animais; provavelmente, a espécie encontrada em $D$. ascanius seja diferente da encontrada em D. gazella, pois a primeira foi atraída por fezes humanas, e a segunda é encontrada em fezes bovinas. Enterococcus causa infecções no trato digestivo e outras patologias a seres humanos (MADINGAN et al., 2004).

Salmonella sp. pode causar intoxicações alimentares graves e é encontrada em fezes de ser humano e restos de alimentos, itens que, segundo observações do autor, são comuns no Parque Olhos D’Água (SCHAECHTER et al., 2002; MADINGAN et al., 2004). Escherichia coli é uma bactéria gram-negativa, bastante comum e estudada, é comum no trato digestivo de mamíferos e aves, podendo causar infecções intestinais e outras patologias ao ser humano (MARINHO et al., 2004). Steinhaus (1941) e Moraes et al. (2004) registraram a presença de E. coli em estudos com tratos digestivos de insetos. Em estudos com a barata Periplaneta americana Linnaeus, $1758 \mathrm{em}$ leitos de hospital, todas as bactérias isoladas, exceto Salmonella sp., foram descritas (MOREIRA et al., 2003).

Observou-se que os besouros da família Scarabaeidae possuem uma flora intestinal diversa, sugerindo que esses organismos podem ser dispersores de fungos e bactérias de importância médica, agrícola e ecológica. O número de espécies de besouros coletadas em um parque urbano relativamente pequeno e altamente antropizado sugere que a diversidade biológica desse grupo da ordem Coleoptera, para o Distrito Federal e para o Bioma Cerrado, seja bastante elevada. 


\section{Microbiota of digestive tract of beetles (Coleoptera: Scarabaeidae) in Parque Olhos D'Água}

\section{Abstract}

Interactions between microorganisms and insects are common in nature and they have medical, agricultural and ecological importance. The objectives of this study were verifying the occurrence of fungi and bacteria from digestive tract of beetles of family Scarabaeidae and knowing the diversity of this group at Parque Olhos D’Água, at Brasilia, DF, Brazil. The insect collects were made using pitfalls, light trap and manual collects, between October 2006 and May 2007. The digestive tract of insects was removed and cultivated in specific culture media for growth of fungi and bacteria. 16 species of beetle were collected, 6 were analyzed and in all of them, there was growth of bacteria of medical importance, like Staphylococcus sp. Fungi of family Saccharomycetaceae represented the major number of species cultivated. The digestive tract of scarab beetles is rich in microorganisms, that are carried and dispersed in their environment.

Key words: Insect fauna. Dung Beetles. Digestive tract. Urban park.

\section{Referências}

ALMEIDA, L. M.; MARINONI, L. Manual de coleta, identificação, conservação e montagem de insetos. Ribeirão Preto: Holos, 2002.

BARRETO, M. R.; BARRETO, E. S.; ANJOS, N. Leveduras associadas a Spermologus rufus Boheman (Coleoptera: Curculionidae). Anais da Sociedade Entomológica do Brasil, Londrina, v. 27, n. 2, p. 295, 1998.

BOTELHO, P. S. M.; CORREA-FERREIRA, B. S.; PARRA, J. R. P. Controle biológico no Brasil: parasitóides e predadores. Barueri: Manole, 2002.

COSTA, C. Biodiversidade do estado de São Paulo, Reino Animalia, In: COLEOPTERA. São Paulo: Biota FAPESP, 1997. v. 5. cap. 12.

GAMA, F. de C.; TEIXEIRA, C.A.D.; VIEIRA, R.X.; COSTA, J.N.M.; GARCIA, A. Fungos associados a Hypothenemus hampei ferrari (Coleoptera, Scolytidae) e aos frutos de Coffea canephora em Machadinho D'oeste, RO, Brasil. Arquivos do Instituto de Biologia, São Paulo, n. 71, p. 169-171, 2002. 
HALFFTER, G.; MATTHEWS, E. G. The natural history of dung beetles of the subfamily Scarabaeinae (Coleoptera: Scarabaeidae). Folia Entomológica Mexicana, México, vol. 12, n. 14, p. 1-312, 1966.

KOHLMANN, B. MORÓN, M. A. Análisis histórico de la classificación de los Coleoptera Scarabaeoidea Lamellicornia. Acta Zoológica Mexicana, México, n. 90, p. 175-280, 2003.

KOLLER, W. W.; GOMES, A.; RODRIGUES, S. R. Controle natural de parasitos em massas fecais bovinas. Brasília, 2002. (Comunicado técnico $\mathrm{n}^{\circ} 72$. Embrapa Gado de Corte).

LEMOS, A. A. et al. Cockroaches as carriers of fungi of medical importance. Mycoses, Germany, v. 49, n. 1, p. 23-25, 2006.

MACEDO, L. D. Estudo Sobre o Perfil do Público Visitante do Parque Olhos D’Água. Brasília, 2003. Trabalho de Conclusão de Curso (Graduação)-Centro Universitário de Brasília.

MADIGAN, M. T.; MARTINKO, J. M.; PARKER, J. Microbiologia de Brock. 10. ed. São Paulo: Prentice Hall, 2004.

MARINHO, M.; MEIRELES, M. V.; SOUZA, A. V. G. Determinação da microflora do trato gastrintestinal de Avestruzes (Struhio camelus) criados na região noroeste do estado de São Paulo. Arquivos do Instituto de Biologia, São Paulo, v. 71, n. 3 , p. 267-271, 2004.

MILHOMEM, M. S.; DINIZ, I. R.; MELLO, F. Z. V. Besouros copro-necrófagos (Scarabaeidae) de um cerrado de Brasília, Distrito Federal, Brasil. In: CONGRESSO DE ECOLOGIA DO BRASIL, 5., 2001 Porto Alegre. Resumos... Porto Alegre: UFRGS, 2001.

MILHOMEM, M. S; MELLO, F. Z. V.; DINIZ, I. R. Técnicas de Coleta de Besouros copronecrófagos no Cerrado. Pesquisa Agropecuária Brasileira, Brasília, v. 38, n. 11, p. 1249-1256, 2003.

MORAES, A. M. L. et al. Fungal Flora of digestive tract of Rhodnius prolixus, Rhodnius neglectus, Diptelanogaster maximus and Panstrongylus megistus, vectors of Trypanossoma cruzi, Chagas, 1909. Brazilian Journal of Microbiology, São Paulo, n. 35, p. 288-291, 2004.

MOREIRA, D. O. et al. Ants as carriers of antibiotic-resistant bacteria in hospitals. 
Neotropical Entomology, Vacaria, v. 34, n. 6, p. 999-1006, 2003.

MORÓN, M. A; ARAGÓN, A. Importância ecológica de las espécies americanas de Coleóptera Scarabaeidae. Dugesiana, México, v. 10, n. 1, p. 13-29, 2003.

OLIVEIRA, J. S. et al. Cladosporium cladosporioides em regiões produtoras de café na Bahia. Bahia Agrícola, Salvador, v. 6, n. 3, p. 73, 2004.

PHAFF, H. J.; STARMER, W. T. Yeasts associated with plants, insects and soil. In: ROSE, A. H.; HARRISON, J. S. (Ed.). The yeasts. Londres: London Academic Press, 1987. p. 123-180.

PUTZKE, J.; PUTZKE, M. T. L. Os reinos dos fungos. Santa Cruz do Sul: Edunisc, 2004. v. 1.

SCHAECHTER, M. et al. Microbiologia: mecanismos das doenças infecciosas. Rio de Janeiro: Guanabara Koogan, 2002.

SCHIFFLER, G; LOUZADA J. N. C. Fatores determinantes da riqueza local de espécies de Scarabaeidae (Insecta: coleoptera) em fragmentos de Floresta Estacional Semidecídua. Lavras, 2003. Tese (Doutorado)-Universidade Federal de Lavras.

STEINHAUS, E. A. A Study of the bacteria associated with thirty species of insects. Ohio: Ohio State University, Department of Bacteriology, 1941.

VAZ-DE-MELLO, F. Z. Scarabaeidae s. str. (Coleoptera: Scarabaeoidea) de um fragmento de Floresta Amazônica no estado do Acre, Brasil. Anais da Sociedade Entomológica do Brasil, Londrina, v. 28, n. 3, p. 447-453, 1999. 
